\title{
Head and Neck Basaloid Carcinoma
}

National Cancer Institute

\section{Source}

National Cancer Institute. Head and Neck Basaloid Carcinoma. NCI Thesaurus. Code C37290.

A high-grade, aggressive variant of squamous cell carcinoma that arises from the head and neck region. The most common sites of origin are pyriform sinus, epiglottis, and base of tongue. It is characterized by the presence of small malignant cells with hyperchromatic nuclei and scant amount of cytoplasm forming lobules with peripheral palisading. Comedonecrosis may be present. 